\title{
Evaluation of foot static disturbances in patients with rheumatic diseases
}

\author{
Anna Kuryliszyn-Moskal ${ }^{1}$, Katarzyna Kaniewska ${ }^{1}$, Zofia Dzięcioł-Anikiej ${ }^{1}$, Piotr Adrian Klimiuk ${ }^{2}$ \\ ${ }^{1}$ Department of Rehabilitation, Medical University of Bialystok, Poland \\ ${ }^{2}$ Department of Rheumatology and Internal Diseases, Medical University of Bialystok, Poland
}

\begin{abstract}
Objectives: Rheumatic diseases such as osteoarthritis and rheumatoid arthritis constitute the most frequent pathological states leading to the development of foot deformities, which reduce quality of life and cause disability. The aim of the present study was to compare the results of plantoconturographic examinations, obtained by means of a computer podoscope, in osteoarthritis and rheumatoid arthritis patients. Special attention was paid to the differences in the values of each parameter determining the level of foot function.

Material and methods: The study was performed in 94 female patients divided into two groups according to the type of disease. There were 54 patients with rheumatoid arthritis and 40 with osteoarthritis. The control group consisted of 34 healthy women. The plantographic assessment of static foot structure was carried out by means of a device for computer-aided foot examination. Results: A fallen transverse arch of the right foot was statistically much more frequent in the rheumatoid arthritis patients than in osteoarthritis patients or the control group $(p<0.005$ and $p<0.05$, respectively). Significant differences in the values of the Wejsflog index were observed in the case of left foot between rheumatoid arthritis patients and the control group $(p<0.05)$. Similarly, there were statistically significant differences in the values of the hallux valgus angle $(\alpha)$ for the right foot between rheumatoid arthritis and osteoarthritis patients or control group (in both cases $p<0.05$ ). Conclusions: Rheumatic diseases predispose patients to disturbances of static foot function. The obtained results highlight the importance of diagnosing foot static disturbances in the prevention of destructive changes affecting the functioning of osteoarthritis and rheumatoid arthritis patients.
\end{abstract}

Key words: foot deformities, hallux valgus, flatfoot.

\section{Introduction}

The human foot is a complex osteoarticular system reinforced by muscles and tendons. Not only does it bear the body weight but also it absorbs shocks during movement [1].

Depending on the source of pathological changes in the osteoarticular system, we can observe differences in the development of foot deformities, which influence the static foot function. Of the numerous pathomechanisms responsible for the development of joint destruction special attention is usually paid to such biomechanical factors as the force of pressure, slip resistance, viscosity of the synovia, as well as changes in the coefficient of friction. Alterations in the biomechanics of the locomotor system result with time in the limitation of joint mobility accompanied by pain syndromes of varying clinical expression and dynamics of progress, joint contractures, limb axis deformations, modified gait pattern coupled with its reduced efficiency, and even emotional and mental changes [2].

Osteoarthritis (OA) and rheumatoid arthritis (RA) belong to the group of pathological conditions leading 
to the development of foot deformities most frequently described in literature [2, 3].

Degenerative changes in the major joints of the lower limbs, such as the knee and hip joints, influence the biomechanics of the entire kinematic chain of the lower extremity. The destructive process that affects joint surfaces and periarticular tissues leads to increased muscle tension as a spontaneous response of the organism, which results in the overload of the biokinematic chain of the lower limb. Incorrect limb positioning gives rise to deformations which, if left untreated, become permanent [4]. Depending on the duration of the disease and the stage of radiological changes, deformations of both the forefoot and rearfoot underlie the development of pathological movement patterns and eventually disability.

Rheumatic diseases constitute some of the most significant pathological conditions promoting the development of foot deformities. Rheumatoid arthritis is a chronic progressive inflammatory process that involves both the joints and periarticular structures. The disease is systemic and it leads to the impairment of locomotive functions, worsening patients' quality of life [5]. Inflammation of the proximal interphalangeal and metatarsophalangeal joints of the foot belongs is a common symptom characteristic for the early stage of RA [6].

Apart from the radiographic examination, there are other techniques that assist in the assessment of foot deformities in RA, such as magnetic resonance imaging (MRI) and ultrasonography (USG). However, the use of these methods is limited due to the necessity of employing highly specialised equipment and professional staff [2]. Plantoconturography coupled with automatic computer analysis of results is one of the latest diagnostic tools applied in the evaluation of static foot disturbances. Plantoconturography constitutes an objective test to evaluate the static foot function, in contrast to the typical physical examination based on a subjective, visual evaluation of foot deformities [7]. This test not only facilitate assessment of foot function, but it also allows diagnosis and graphic documentation of static foot disturbances $[8,9]$.

Osteoarthritis and rheumatoid arthritis are the most frequent causes that lower static foot function [10, 11]. The aim of the study was to assess static foot function in patients with primary osteoarthritis and rheumatoid arthritis based on selected stabilometric parameters in plantographic examination.

\section{Material and methods}

The study was carried out in the Rehabilitation Department of the Medical University of Bialystok Clinical
Hospital after obtaining approval from the Bioethics Committee of the Medical University in Bialystok. All the patients consented to the study.

Fifty-four women with stages II and III of rheumatoid arthritis, following Steinbrocker's radiological stage classification, were included in the study [12]. Their mean age was $58.6 \pm 9.4$ years and the range was $35-75$ years. Forty women with osteoarthritis of knee joints also participated in the study. Their mean age was $60.7 \pm 10.29$ years ranging between 42 and 82 years. The control group (CG) comprised 34 women aged 24-60 years, their mean age was $42.08 \pm 13.3$ years.

Women with disorders that may result in static feet disturbances, such as diabetes and low back pain caused by lumbar discopathy, were excluded from the study. Additionally, the exclusion criteria included: pregnancy, post-traumatic and post-operative state of lower limbs. Due to the methodology of plantoconturographic examination, patients with RA who were not able to stand without the help of others were also excluded from the study.

\section{Plantoconturographic examination}

The plantoconturographic examination was carried out by means of a podoscope with a spatial scanner and computer-aided foot examination software CQ ST2K (Świerc-Poland).

The following parameters were determined: hallux valgus angle $(\alpha)$ (the angle between a line drawn from the medial edge of the foot and a line from the widest part of the forefoot to the outside edge of the hallux) was measured. The normal value is 0-90 [13].

The Wejsflog index $(W)$ determines the ratio between the length and width of the foot; its physiological proportion is $3: 1$. Values between 2 and 3 are considered to be within acceptable limits. Values closer to 2 are associated with a fallen transverse arch, whereas those approximating 3 exclude abnormalities in the transverse $\operatorname{arch}[13]$.

In addition, Clarke's angle (CL), which is formed at the intersection of a line that joins the most internal points of the forefoot and the rearfoot and the internal line, was also measured. The value of Clarke's angle indicates as follows: flatfoot $\leq 30^{\circ}$, foot with a lower arch $31-41^{\circ}$, foot with a normal arch $42-54^{\circ}$, foot with a higher $\operatorname{arch} \geq 55^{\circ}[13]$.

\section{Statistical analysis}

In order to compare presentations of qualitative features, the $\chi^{2}$ test of independence and Fisher's exact test were applied. Normal distribution was verified by the Kolmogorov-Smirnov test with Lilliefors correc- 
tion and the Shapiro-Wilk test. No normal distribution of the analysed variables was established. Comparing quantitative variables with no normal distribution the non-parametric ANOVA Kruskal-Wallis test by ranks with post-hoc test for multiple comparisons of mean ranks for all the samples, in the case of multiple groups, were used. Results were considered statistically significant for $p<0.05$. Calculations were performed by means of Statistica 10.0 software produced by StatSoft and PASW Statistics 17.0 produced by Predictive Solutions.

\section{Results}

On the basis of the Wejsflog index (W), we established statistically significant differences in the prevalence rates of a fallen transverse arch of the right foot in patients with RA or OA as compared to the control group. Values of the $W$ index $\leq 2.5$ were found significantly more often among RA patients (50\%) and OA patients (35\%) as compared to healthy volunteers (17.7\%) ( $p<0.01$ and $p<0.05$, respectively). No meaningful differences were observed in the prevalence rates of a fallen transverse arch of the left foot. Nevertheless, the prevalence rate of feet with a lower arch of the left foot was about 20\% in the RA patients and healthy subjects, whereas in the case of the OA patients it amounted to $12.5 \%$ (Fig. 1).

Statistical analysis of the studied parameters showed also statistically significant lower values of the Wejsflog index for the left foot between RA patients $(\mathrm{Me}=2.59)$ and the control group $(\mathrm{Me}=2.72)(p=$ 0.002) (Table I).

Based on the value of the $\alpha$ angle, the prevalence rate of hallux valgus of the right foot was significantly higher in the RA patients compared to the OA patients and the control group ( $p<0.01$ in both cases) (Fig. 2).

In addition, significant differences in the values of the $\alpha$ angle for right foot were established between the RA patients (Me $R=11.8$ ) and the control group

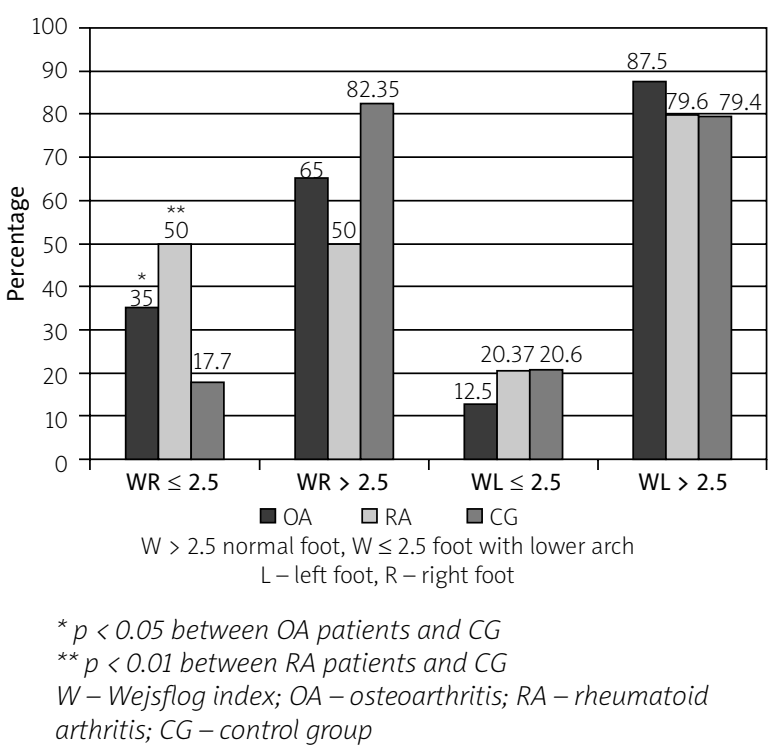

Fig. 1. Percentage of prevalence of transverse arch pathology based on the value of the Wejsflog index.

(Me $R=4.75)(p=0.001)$. Similarly, we found significant differences in the values of the $\alpha$ angle for the right foot between the RA patients $(\mathrm{Me}=11.8)$ and the generalised group of OA patients $(\mathrm{Me}=8.1)(p=0.001)$ (Table II). In case of the left foot no significant differences were observed.

No significant differences between the studied groups were established with regard to Clarke's angle or the prevalence rate of longitudinal arch pathology based on the value of Clarke's angle (Table III).

\section{Discussion}

Rheumatoid arthritis is characterised by the development of non-specific synovitis which brings on deformities of articular and periarticular structures. Williams et al. [14] indicate that complaints concerning small joints of the

Table I. Values of the Wejsflog index in the studied groups

\begin{tabular}{|c|c|c|c|c|c|c|c|c|}
\hline \multirow[t]{2}{*}{ Parameter } & \multicolumn{8}{|c|}{ Wejsflog index } \\
\hline & Foot & Mean & $\mathrm{Me}$ & Min & Max & $\mathrm{Q}_{1}$ & $\mathrm{Q}_{2}$ & $\mathrm{SD}$ \\
\hline \multirow[t]{2}{*}{$\mathrm{OA}$} & $\mathrm{R}$ & 2.61 & 2.61 & 2.28 & 3.29 & 2.46 & 2.71 & 0.21 \\
\hline & $\mathrm{L}$ & 2.70 & 2.67 & 2.27 & 3.73 & 2.56 & 2.80 & 0.26 \\
\hline \multirow[t]{2}{*}{ RA } & $R$ & 2.50 & 2.50 & 1.99 & 2.89 & 2.38 & 2.63 & 0.17 \\
\hline & $\mathrm{L}$ & 2.57 & 2.59 & 1.89 & 2.89 & 2.52 & 2.66 & 0.17 \\
\hline \multirow[t]{2}{*}{$C G$} & $\mathrm{R}$ & 2.56 & 2.56 & 2.27 & 2.93 & 2.51 & 2.64 & 0.14 \\
\hline & L & 2.70 & 2.72 & 2.40 & 3.14 & 2.55 & 2.83 & 0.17 \\
\hline
\end{tabular}

$O A$ - osteoarthritis; $R A$ - rheumatoid arthritis; $C G$ - control group; $R$ - right; $L$ - left 


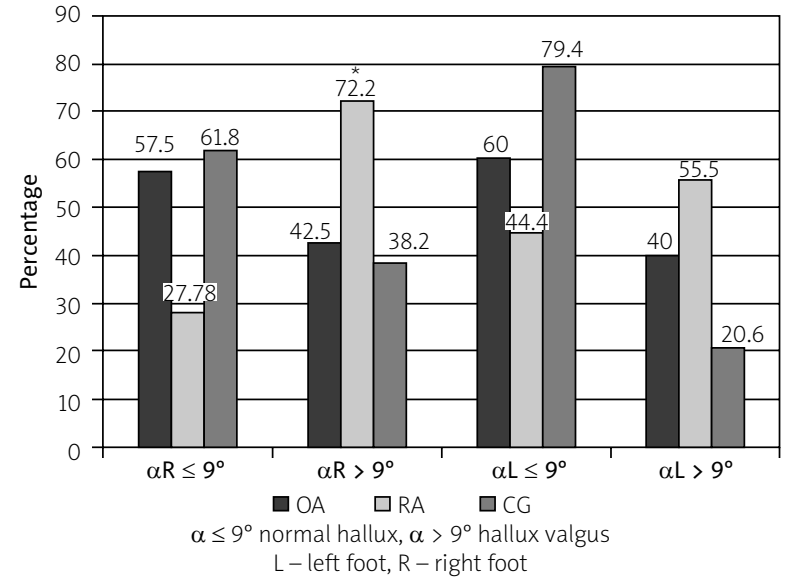

${ }^{*} p<0.01$ between RA patients and OA patients or CG $O A$ - osteoarthritis; $R A$ - rheumatoid arthritis; $C G$ - control group

Fig. 2. Percentage of prevalence of the first metatarsophalangeal joint pathology based on the value of the $\alpha$ angle.

hands and feet are the most frequent reasons for which patients visit general practitioner (GP) clinics. It is worth highlighting that $100 \%$ of RA patients will experience foot problems within the first 10 years of disease [15].

The pathological image of the foot in RA reflects static foot function disturbances, which may result in disability [16]. The clinical picture of the foot in RA includes a number of pathological foot changes, such as: hallux valgus, subluxation of the metatarsophalangeal joints, pes valgus, as well as swelling around the ankles and metatarsophalangeal joints. Foot deformities lead to reduced mobility of the joints and pain.

According to the latest research, both erosion and articular space narrowing in the metatarsophalangeal joints and the first interphalangeal joint, assessed by means of radiographic examination, affects $37 \%$ of patients in the early stage of the disease [17].

The authors of other studies, in which plantoconturography was applied for evaluation of foot statics in patient with RA, have reported that the most striking differences with regard to the $\alpha$ angle were observed in women with radiological stage III of RA. Higher values of the $\alpha$ angle were observed in $80 \%$ of the examined patients with radiological stage III of RA [7].

The results of our studies confirm the above-mentioned outcomes and exhibit an increasing trend in the prevalence rate of the pathological changes affecting the first metatarsophalangeal joint. Hallux valgus, reflecting the destruction of these joints, was found in $55 \%$ of the left feet and $72.2 \%$ of the right feet in RA of stage II and III.

The development of osteoarthritis leads to the destruction of cartilage and the subchondral layer, and degeneration affecting all the articular structures. For example, degeneration of the knee joint, which constitutes a pathological link in the kinematic chain, results

Table II. Values of the hallux valgus angle $(\alpha)$ in the studied groups

\begin{tabular}{|lccccccccc|}
\hline Parameter & \multicolumn{7}{c|}{ Mallux valgus angle $(\alpha)$} \\
\cline { 2 - 10 } & Foot & Mean & Me & Min & Max & $\mathrm{Q}_{1}$ & $\mathrm{Q}_{2}$ & SD \\
\hline OA & $\mathrm{R}$ & 7.83 & 8.10 & -9.00 & 36.80 & 0.15 & 13.35 & 10.02 \\
\cline { 2 - 10 } & $\mathrm{L}$ & 8.11 & 6.00 & -4.40 & 32.20 & 2.10 & 14.60 & 8.34 \\
\hline RA & 12.92 & 11.80 & 0.70 & 33.60 & 7.40 & 17.90 & 7.39 \\
\hline CG & $\mathrm{R}$ & 12.26 & 10.20 & 0.60 & 46.00 & 6.40 & 18.20 & 9.29 \\
\hline & $\mathrm{L}$ & 6.05 & 4.75 & -12.40 & 22.80 & 0.40 & 11.30 & 9.10 \\
\hline
\end{tabular}

$O A$ - osteoarthritis; RA - rheumatoid arthritis; $C G$ - control group; $R$ - right; $L$ - left

Table III. Statistically significant differences in the analyzed plantoconturographic parameters

\begin{tabular}{|lcccccc|}
\hline Parameters & \multicolumn{2}{c}{ Wejsflog index } & \multicolumn{2}{c}{$\alpha$ angle } & \multicolumn{2}{c|}{ Clarke's angle } \\
\cline { 2 - 7 } & $\mathrm{R}$ & $\mathrm{L}$ & $\mathrm{R}$ & $\mathrm{L}$ & $\mathrm{R}$ & $\mathrm{L}$ \\
\hline OA-RA & $\mathrm{ns}$ & $\mathrm{ns}$ & $p<0.01$ & $\mathrm{~ns}$ & $\mathrm{~ns}$ & $\mathrm{~ns}$ \\
\hline OA-CG & $p<0.05$ & $\mathrm{~ns}$ & $\mathrm{~ns}$ & $\mathrm{~ns}$ & $\mathrm{~ns}$ & $\mathrm{~ns}$ \\
\hline RA-CG & $p<0.01$ & $p=0.002$ & $p<0.01$ & $\mathrm{~ns}$ & $\mathrm{~ns}$ & $\mathrm{~ns}$ \\
\hline
\end{tabular}

$O A$ - osteoarthritis; $R A$ - rheumatoid arthritis; $C G$ - control group; $R$-right; $L$ - left 
in the development of similar changes in the hips, spine, and feet. Functional disorders linked to the structural and morphological changes within the lower limbs contribute to impaired joint mobility, pain syndromes, axial deformity of the joints, and, thereby, changes in the gait pattern coupled with its limited efficiency [18].

Furthermore, research results reveal a relationship between the functional state of the musculoskeletal system of the lower limbs and changes in the structure of the foot arch [19]. Degenerative changes affecting the medial knee compartment exert an influence on foot morphology, disturbing its mobility [20]. On the basis of pedobarographic examination, it was shown that in patients suffering from the degenerative disease of the hips, the plantar surface loading distribution was not even and the body weight was evidently shifted onto the healthy limb [21]. As is the case in RA, the most common types of foot deformities in OA are those of the longitudinal and transverse arches, as well as of the first metatarsophalangeal joint $[22,23]$. Recent research confirms the relation between the degree of pain intensity and the development of degenerative changes in the knee and feet joints and a fallen longitudinal arch [24].

Few studies have been devoted to the assessment of the degree of severity of foot function disturbances on the basis of plantoconturographic examination. All authors agree, concerning application of this method, to monitoring the biomechanical changes in RA patients [25].

The most common tool in the assessment of foot deformities in RA is radiographic examination. According to the latest research, however, radiography is not sufficiently sensitive method, especially in the early stages of RA as it cannot always be relied on to fully reflect the degree of severity of the clinical changes in RA [26].

Plantoconturographic examination provides a detailed diagnosis of foot statics disturbances and facilitates collecting and analysing results in a repetitive and comparable manner. Apart from an accurate footprint, it also delivers information about the spatial shape of the foot arch.

However, few studies have analysed anthropometric indices measured by means of plantoconturographic examination in the course of the locomotor system disorders. There are no reports on the differences in foot anthropometric values in patients with generalised OA and RA.

The studies by Szaporów and Golec [27], which present changes in the anthropometric parameters of the feet following bilateral alloplasty of the knee joint with cemented endoprostheses, showed the existence of a fallen longitudinal arch in OA patients. Interesting results on the coincidence of flat feet with degenerative changes in the joints of the lower limbs were presented by Rzaniak et al. [28]. The authors noticed a decline in the mean values of Clarke's angle in patients with gonarthrosis compared to healthy controls. Also, Rongies et al. [29] evaluated the foot arch in patients with gonarthrosis and coxarthrosis. The obtained results showed that none of the patients suffering from the degenerative disease of the knee joints had a correctly arched foot. On the basis of the value of Clarke's angle, the authors diagnosed a fallen longitudinal arch in $60 \%$ of their patients. The remaining subjects had a lower foot arch. Similarly, in the majority of patients suffering from gonarthrosis the values of Clarke's angle were lower than $41^{\circ}$. In the present study the mean value of Clarke's angle in the OA patients amounted to approximately $54^{\circ}$, whereas in $25 \%$ of the patients the value of Clarke's angle was lower or equal to $45.3^{\circ}$ [29].

Static feet efficiency in patients with RA and generalised OA has not been reported in the literature as yet. In the present study the evaluation of static foot disturbances in patients with RA and generalised OA was based on the results of plantoconturographic examinations. The results reveal differences in disorders influencing the structure of the foot arch, especially in the case of hallux valgus and a fallen transverse arch. A fallen transverse arch of the right foot was statistically much more frequent in the RA patients than in the OA patients or the control group. Significant differences in the values of the Wejsflog index were observed between RA patients and the control group. Similarly, there were statistically significant differences in the values of the hallux valgus angle ( $\alpha$ ) for the right foot between RA and OA patients or control group.

\section{Conclusions}

Evaluation of static foot disturbances in the course of rheumatic diseases appears to be useful both for the monitoring and proper planning of the therapeutic management of patients, as well as for the assessment of its efficacy, and it ought to be incorporated into the diagnostics. Plantoconturography coupled with automatic computer analysis of the results constitutes one of the tools for evaluation, diagnosis, and documentation of foot mechanics disturbances.

The authors declare no conflict of interest.

\section{References}

1. Lin YC, Kwon JY, Ghorbanhoseini M, et al. The hindfoot arch what role does the imager play? Radiol Clin N Am 2016; 54: 951-968.

2. Graham CL, Chapman J. Biomechanics of the ankle. Orthop Trauma 2016; 30: 232-238. 
3. Barrois R, Gregory T, Oudre L, et al. An automated recording method in clinical consultation to rate the limp in lower limb osteoarthritis. PLoS One 2016 Oct 24; 11(10): e0164975.

4. Yılmaz B, Kesikburun S, Keoroglu O, et al. Effects of two different degrees of lateral-wedge insoles on unilaterallower extremity load-bearing line in patients with medial knee os teoarthritis. Acta Orthop Traumatol Turc 2016; 50: 405-408.

5. Carter K, Lahiri M, Cheung PP, et al. Prevalence of foot problems in people with inflammatory arthritis in Singapore. J Foot Ankle Res 2016; 9: 235-240.

6. Lunz D, Cadden A, Negrine, et al. The weil ostetomy: indications, surgical technique and fixation. J Bone Joint Surg $\mathrm{Br}$ 2010; 92-B Suppl 1:179.

7. Dzięcioł Z, Kuryliszyn-Moskal A, Dzięcioł J. Application of plantography examination to the assessment of foot deformity in patients with rheumatoid arthritis. Arch Med Sci 2015; 11 1015-1020.

8. Vidmar G, Novak P. Reliability of in-shoe plantar pressure measurements in rheumatoid arthritis patients. Int J Rehabi Res 2009; 32: 36-40.

9. Yavuz M, Husni E, Botek G, et al. Plantar shear stress distribution in patients with rheumatoid arthritis: relevance to foot pain. J Am Podiatr Med Assoc 2010; 100: 265-269.

10. Roma I, de Almeida ML, da Silva Mansano N, et al. Quality of life in adults and elderly patients with rheumatoid arthritis. Rev Bras Rheumatol 2014; 54: 279-286.

11. Stucki G. Understanding disability. Ann Rheum Dis 2003; 62: 289-290.

12. Steinbrocker O, Traeger CH, Batterman RC. Therapeutic criteria in rheumatoid arthritis. JAMA 1949; 140: 659-662.

13. Świerc A. Komputerowa diagnostyka stóp - instrukcja obsługi. Czernica Wrocławska 2009

14. Williams AE, Graham AS. My feet- visible, but ignored. A qualitative study of foot care for people with rheumatoid arthritis. Clin Rehabil 2012; 26: 952-959.

15. Shi K, Tomita T, Hayashida K, et al. Foot deformities in rheumatoid arthritis and relevance of disease severity. J Rheumatol 2000; 27: 84-89.

16. Brooks F, Hariharn K.The rheumatoid forefoot. Curr Rev Musculoscelet Med 2013; 6: 320-327.

17. Hulsmans HM, Jacobs JW, van der Heijden DM, et al. The course of radiological damage during the first six years of rheumatoid arthritis. Arthritis Rheum 2000; 43: 1927-1931.
18. Chapman GJ, Halstead J, Redmond AC. Comparability of off the shelf foot orthoses in the redistribution of forces in midfoot osteoarthritis patients. Gait Posture 2016; 49: 235-240.

19. Reilly K, Baker K, Shamley D, et al. The role of foot and ankle assessment of patient with lower limb osteoarthritis. Physiotherapy 2009; 95: 164-169.

20. Lavinger P, Menz HB, Morrow AD, et al. Foot kinematics in people with medial compartment knee osteoarthritis. Rheumatology 2012; 51: 2191-2198.

21. Rongies W, Bąk A, Lazar A. Próba wykorzystania badania pedobarograficznego do oceny skuteczności rehabilitacji osób z chorobą zwyrodnieniową stawów biodrowych. Ortop Traumatol Rehab 2009; 3: 245-252.

22. Klugarova J, Janura M, Svoboda Z, et al. Hallux valgus surgery affects kinematic parameters during gait. Clinical Biomechanics 2016; 40: 20-26.

23. Huang YC, Wang LY, Wang HC, et al. The relationship between the flexible flat foot and plantar fasciitis: ultrasonographic evaluation. Chang Gung Med J 2004; 27: 443-448.

24. Riskowski JL, Dufour AB, Hagedorn TJ, et al. Associations of foot posture and function to lower extremity pain; results from a population- based foot study. Arthritis Care Res (Hoboken) 2013; 11: 1804-1812.

25. Kuryliszyn-Moskal A, Kaniewska K, Konarzewski P, et al. Wspótczesne metody diagnostyki i terapii zaburzeń wydolności statycznej stóp w przebiegu reumatoidalnego zapalenia stawów. Reumatologia 2012; 50: 507-511.

26. Ejbjerg B, Vestergaard A, Jacobsen S, et al. The smallest detectable difference and sensitivity to change of magnetic resonance imaging and radiographic scoring of structural joint damage in rheumatoid arthritis finger, wrist, and toe joints. Arthritis Rheum 2005; 52: 2300-2306.

27. Szaporów T, Golec E. Ocena wybranych parametrów antropometrycznych stóp u chorych po alloplastyce dwuprzedziatowej stawu kolanowego endoprotezami. Ostry Dyżur 2013; 6: 81-85.

28. Rzaniak E. Wpływ zmian zwyrodnieniowych stawów biodrowych na ukształtowanie stopy. Kwartalnik Ortopedyczny 2007; 3: 342-351.

29. Rongies W, Pawłowski M, Choromańska J, et al. Ocena wysklepienia stopy u pacjentów z chorobą zwyrodnieniową stawów biodrowych. Acta Balneologica 2010; 4: 245-254. 